\title{
STUDY ON SEISMIC PERFORMANCE EVALUATION OF MODERN WOODEN SCHOOL BUILDINGS IN JAPAN
}

\author{
MITSUHIRO MIYAMOTO ${ }^{1 *}$ \\ ${ }^{1}$ Kagawa University \\ Faculty of Engineering and Design \\ 2217-20, Hayashi-cho, Takamatsu City, Kagawa Prefecture, Japan \\ e-mail: miyamoto@eng.kagawa-u.ac.jp
}

Keywords: Modern Wooden School Building, Static Pushover Analysis, Seismic Performance

\begin{abstract}
Japanese school buildings have been changed from modern wooden structures to reinforced concrete structures after the Building Standard Law was established in 1950. Therefore, only a few modern wooden school buildings exist currently. Ensuring the seismic resilience of these wooden school buildings is essential for their preservation and longevity. In this study, a static pushover analysis was conducted for a modern wooden school building using a $3 D$ frame model to simulate the relationship between lateral load and deformation. This $3 D$ frame model was proposed based on the site investigation and the $2 D$ frame model used in a previous study. From the analysis results, it is found that the bearing capacity was decided by the deformation capacity of the column-to-groundsill connection; therefore, reinforcement to these connections was required to improve the seismic performance of a modern wooden school building.
\end{abstract}

\section{INTRODUCTION}

The structural characteristics of the modern wooden school buildings are different from other Japanese wooden buildings. The main seismic elements are large section braces and knee braces. All braces and knee braces were fixed to the column using steel bolts. The column was connected to the beam or groundsill using metal connectors on each side of a connection.

Several studies in Japan focused on the seismic performance of wooden brace frames. However, only a few studies have focused on the large section brace used in modern wooden school buildings. In addition, a small number of studies have addressed the wooden knee braces. Thus, almost no experimental data are available for evaluating the seismic performance of modern wooden school buildings.

The objective of this paper is to develop a 3D-frame model for the seismic performance evaluation of modern wooden school buildings. In a previous study [1], full-scale static lateral loading tests were conducted for wooden frames, single braces, cross braces, and knee brace specimens to examine the fracture modes and the relationship between the lateral load and deformation. These four specimens were designed based on the site investigation of existing modern wooden school buildings. In addition, a static pushover analysis was carried out for these specimens using a 2D-frame model to simulate the relationship between lateral load and deformation. The analysis models were developed and compared with test results to examine 
their validity. The analysis results were in good agreement with the test results.

In the present study, a static pushover analysis was carried out for a modern wooden school building using a 3D-frame model to simulate the relationship between lateral load and deformation. The 3D-frame model was proposed based on the site investigation and 2D-frame model. Based on the analysis results, the bearing capacity and deformation capacity of a modern wooden school building were evaluated.

\section{OUTLINE OF A MODERN WOODEN SCHOOL BUILDING}

The north and east school buildings of Yashiro Junior High School, which are the target modern wooden school buildings of this study, are wooden structures located in Ehime Prefecture. These buildings were built in 1960 and 1961. The buildings were dismantled recently. However, we were presented with an opportunity to investigate their structural characteristics before they were dismantled. Figure 1 shows the north school building. The main seismic elements are large section braces and knee braces (Figures 2 to 10). The dimensions of the column, groundsill, and the brace are $135 \times 135 \mathrm{~mm}$, and those of the beam and knee brace are $135 \times 135 \mathrm{~mm}$ or $150 \times 150 \mathrm{~mm}$ and $90 \times 90 \mathrm{~mm}$, respectively. All braces and knee braces were fixed to the column using a bolt with a diameter of $12 \mathrm{~mm}$. The column was connected to

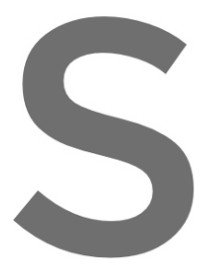

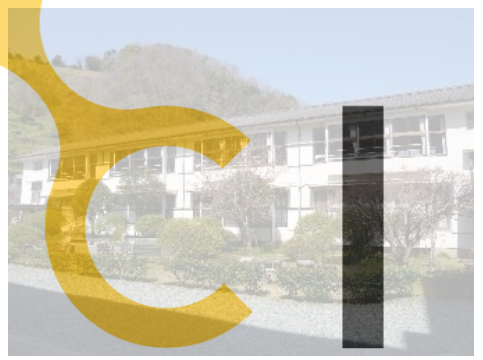

Figure 1: Façade of a modern

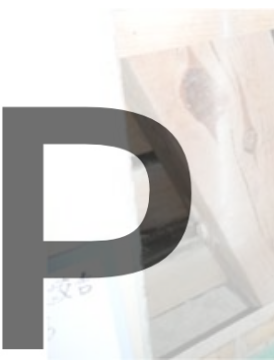

Figure 2: Edge of a timber brace

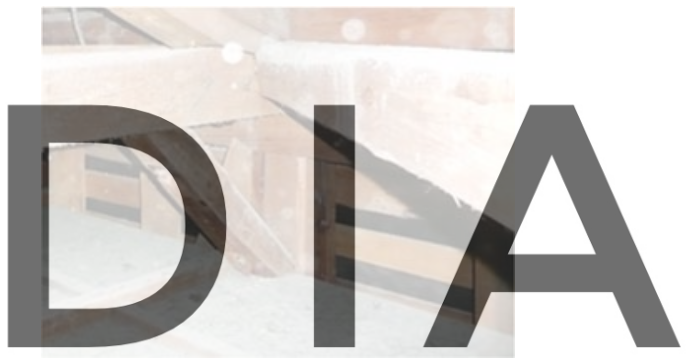

Figure 3: Overview of a knee

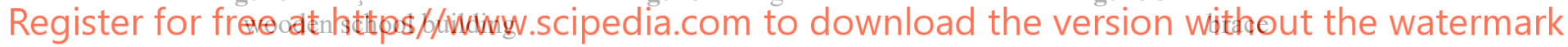

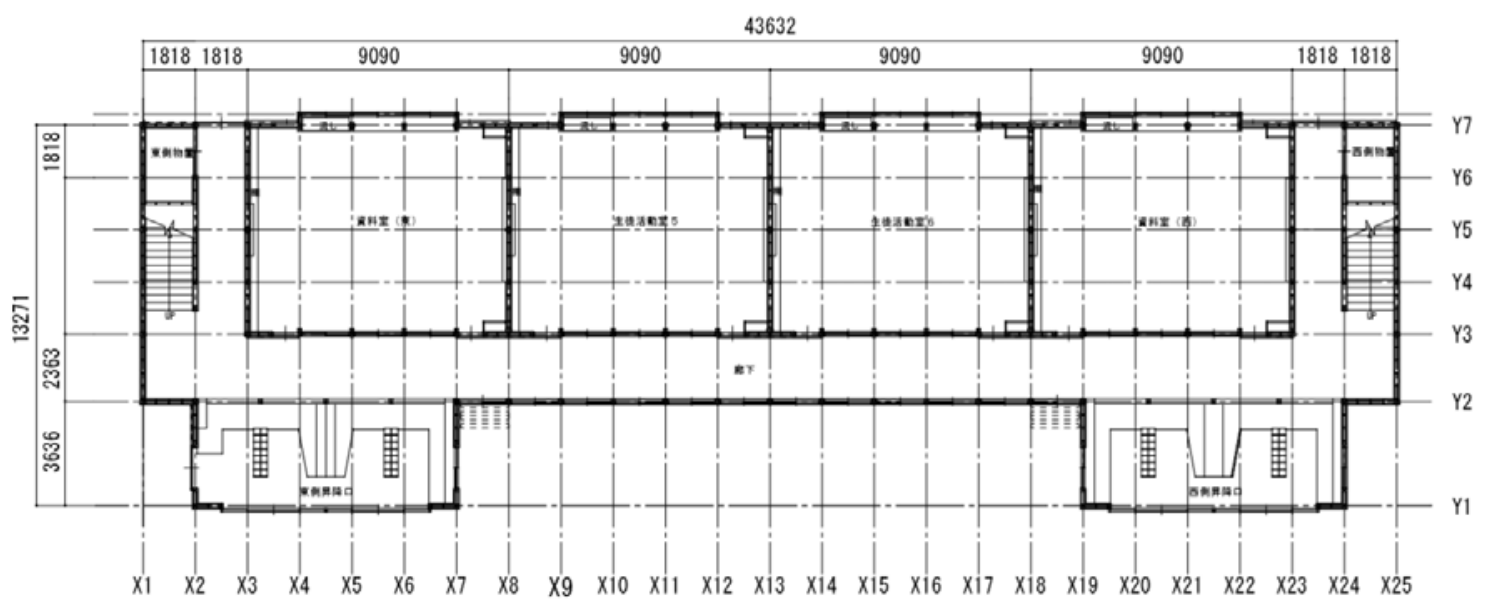

Figure 4: Plan of ground floor 


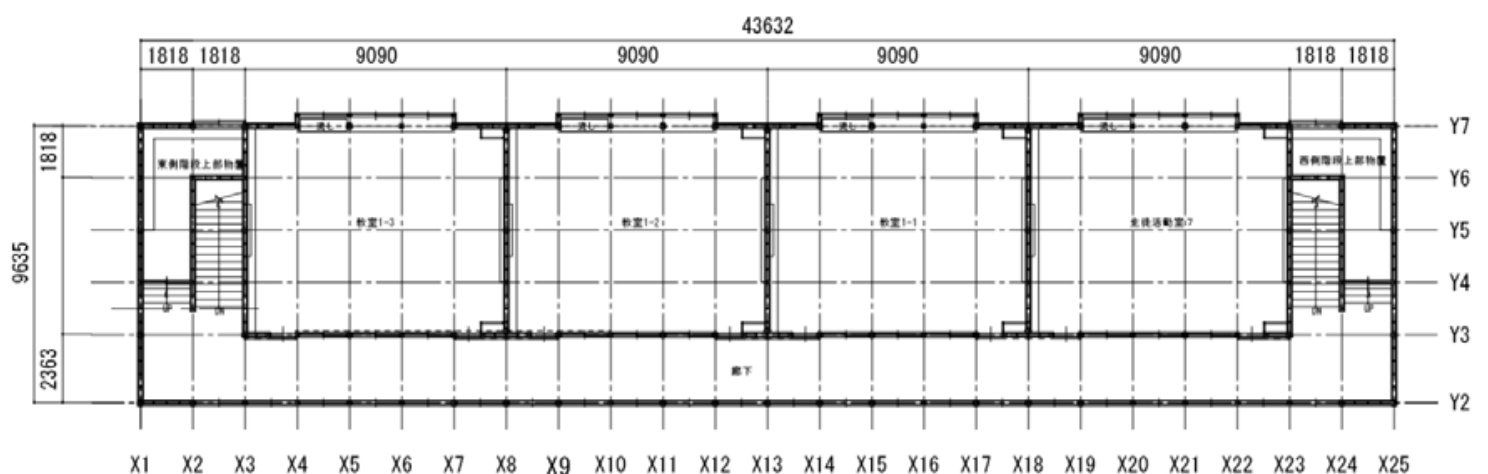

Figure 5: Plan of first floor

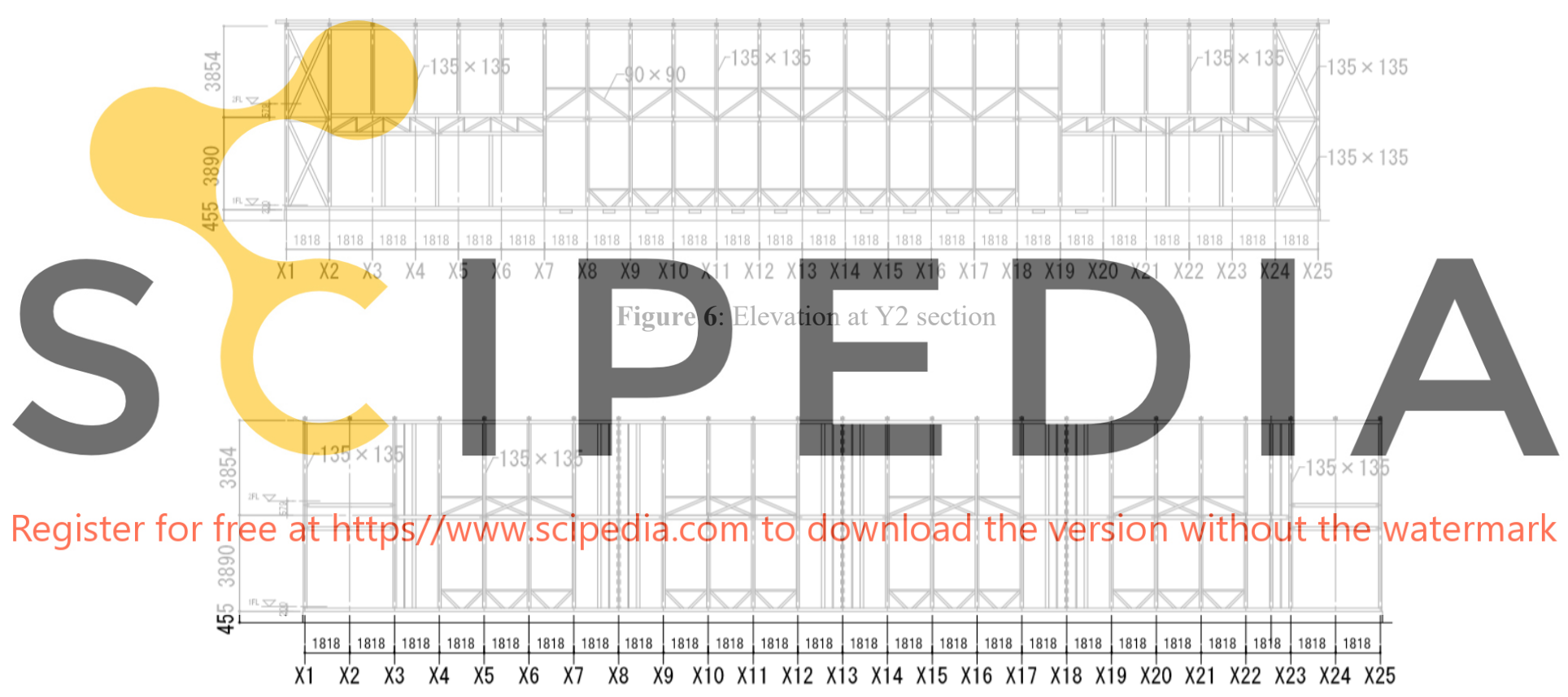

Figure 7: Elevation at Y3 section

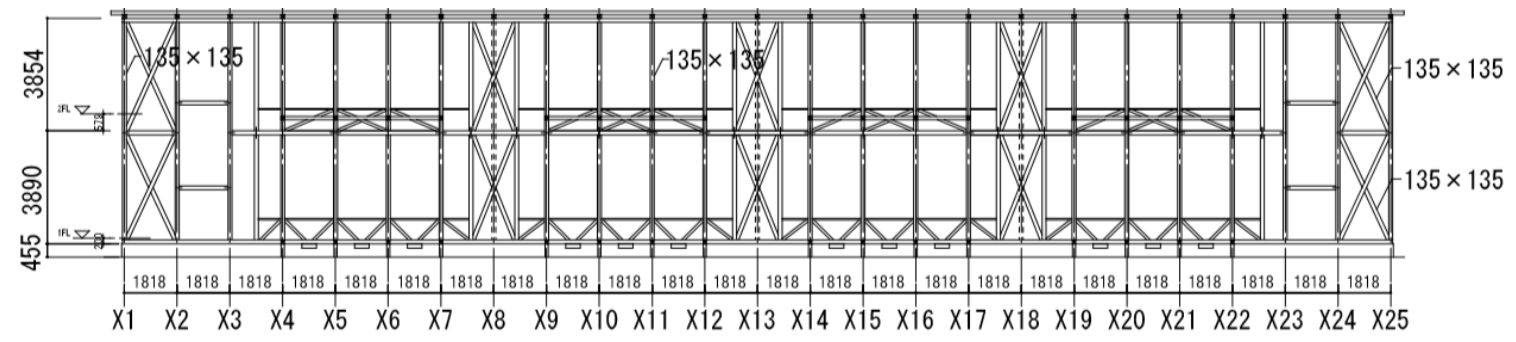

Figure 8: Elevation at $Y 7$ section 


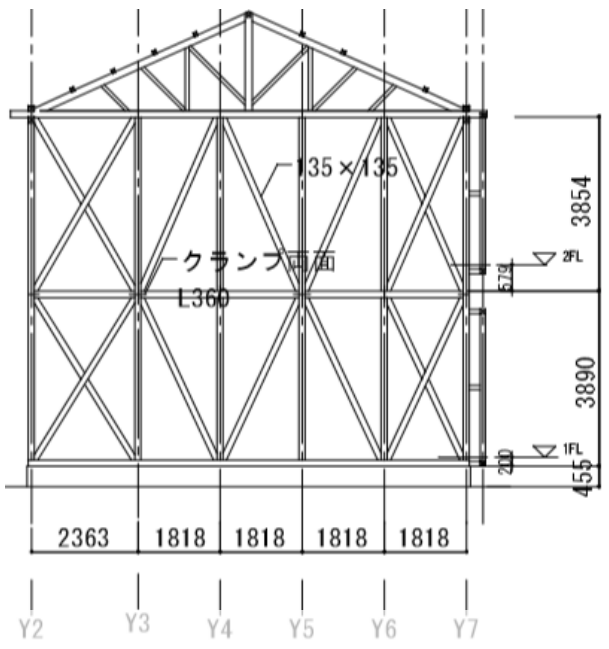

Figure 9: Elevation at X1 and X25 section

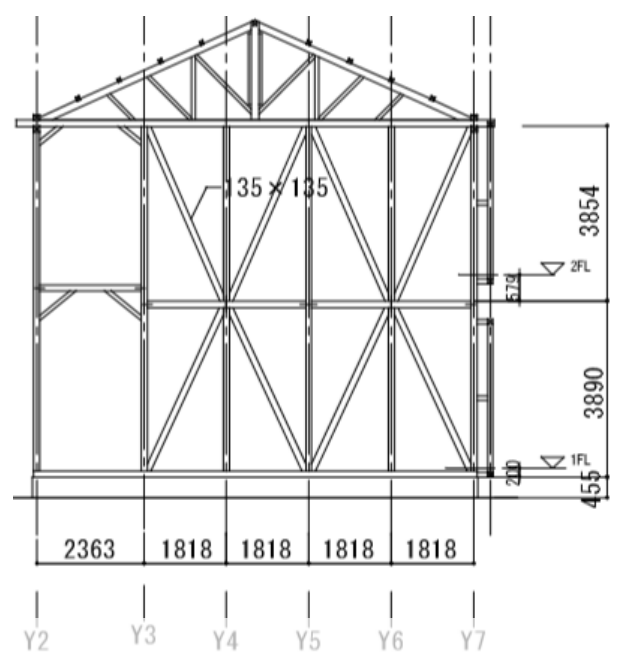

Figure 10: Elevation at X8, X13 and X18 section

the beam or groundsill using metal connectors on each side of a connection.

\section{3D FRAME MODEL FOR A MODERN WOODEN SCHOOL BUILDING}
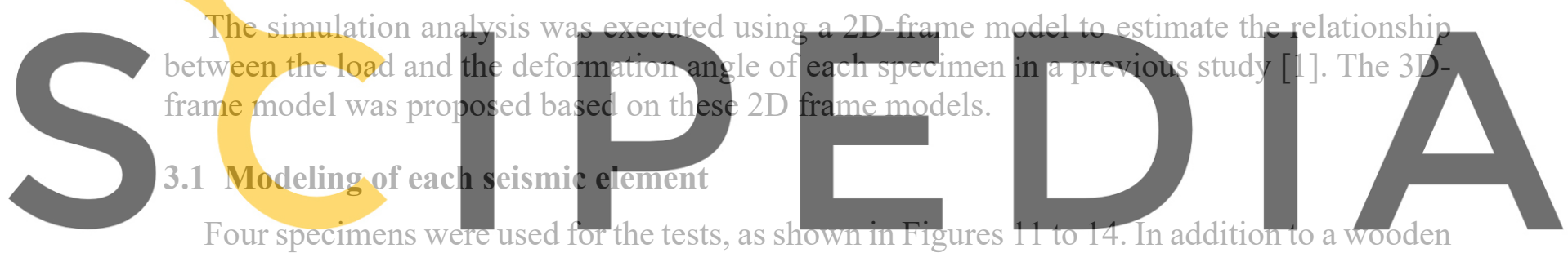

frame specimen, single brace, cross brace, and knee brace specimens were also used because

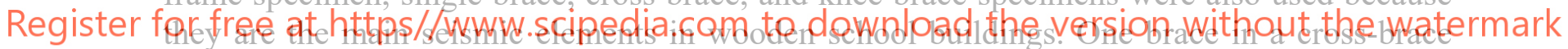

specimen was separated at the intersection. The height and width of each specimen were 2752.5

$\mathrm{mm}$ and $1820 \mathrm{~mm}$, respectively. The dimensions of the column, groundsili, and the brace were $135 \times 135 \mathrm{~mm}$ and those of the beam and knee brace were $135 \times 180 \mathrm{~mm}$ and $90 \times 90 \mathrm{~mm}$, respectively. The column and brace were made of cedar, the beam and knee brace were made of Douglas fir, and the groundsill was made of Japanese cypress. All connections were designed

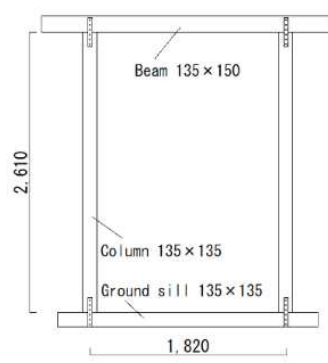

Figure 11: Outline of specimen A

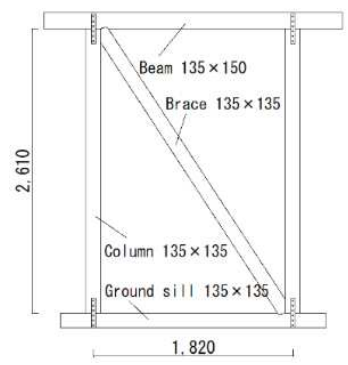

Figure 12: Outline of specimen B

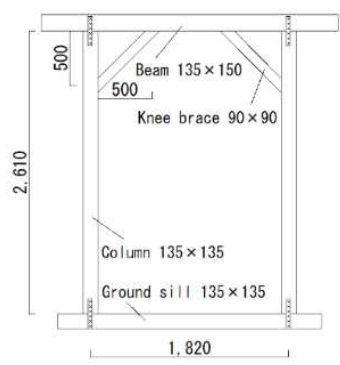

Figure 13: Outline of specimen $\mathrm{C}$

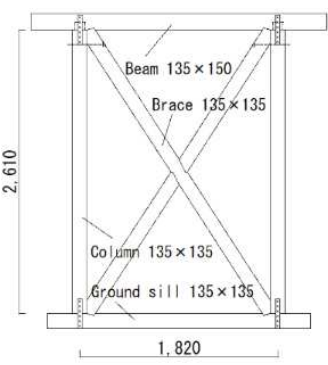

Figure 14: Outline of specimen D 
to be the same as those of actual wooden school buildings based on the site investigation. In the column-to-brace connection, the brace was connected to the beam or groundsill with a depth of $15 \mathrm{~mm}$. The column was connected to the beam or groundsill using a short tenon with a height, width, and thickness of $67.5 \mathrm{~mm}, 90 \mathrm{~mm}$, and $30 \mathrm{~mm}$, respectively. Similarly, in the column-to-knee brace connection, the knee brace was connected to the column with a depth of $15 \mathrm{~mm}$. In addition, metal connectors were fixed on each side of the connection using six nails. The height, width, and thickness of the metal connectors were $270 \mathrm{~mm}, 40 \mathrm{~mm}$, and $5 \mathrm{~mm}$, respectively. The through brace, separate brace, and knee brace were fixed on the column using a bolt with a diameter of $12 \mathrm{~mm}$. These specimens were subjected to cyclic lateral loads, with the real shear deformation angle being gradually increased symmetrically from $1 / 450,1 / 300$, $1 / 200,1 / 150,1 / 100,1 / 75,1 / 50,1 / 30,1 / 20$ to $1 / 15 \mathrm{rad}$. Three cyclic loadings were applied. Finally, the specimen was loaded to $1 / 10 \mathrm{rad}$ at one end.

Figures 15 to 20 show the analysis model used for the static pushover analysis. The analysis models of specimens B and D were assumed to be different because the resistance element of a through brace was different for tensile and compressive braces. The bending resistance at the connection of the metal connector and short tenon was expressed as a rotation spring. The rotation springs of these connections with a through brace on specimens B (compression) and $\mathrm{D}$ were excluded because there was a brace to prevent the connection from rotating. The uplift behavior at one side of the column-to-groundsill connection on specimens B (compression) and D was expressed as an axis spring based on the results of following tests. The tensile test for
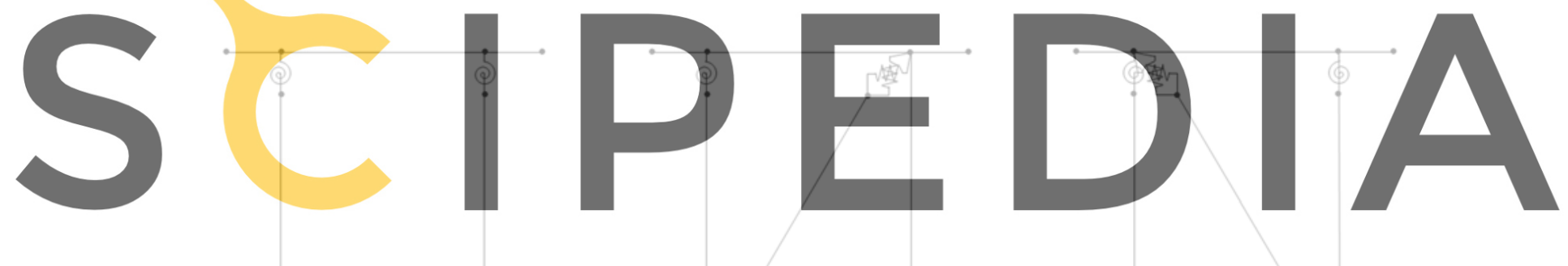

Register for free at https//www.scipedia.com to download the version without the watermark

Figure 15: Mechanical model of specimen A

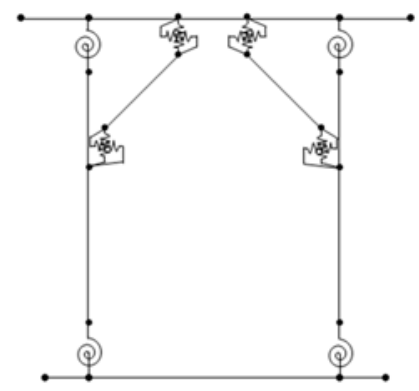

Figure 18: Mechanical model of specimen $\mathrm{C}$
Figure 16: Mechanical model of specimen B (Compression)

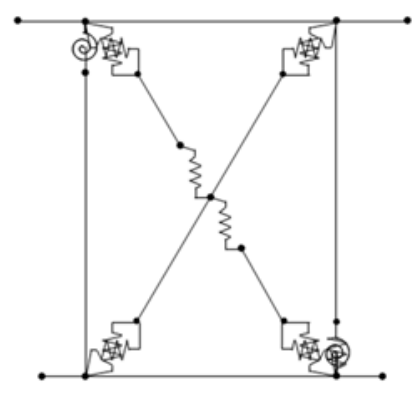

Figure 19: Mechanical model of specimen D (Compression)
Figure 17: Mechanical model of specimen B (Tensile)

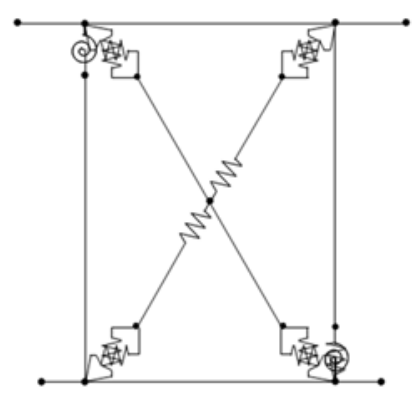

Figure 20: Mechanical model of specimen D (Tensile) 


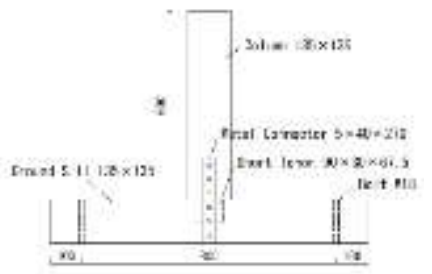

Figure 21: Outline of specimen

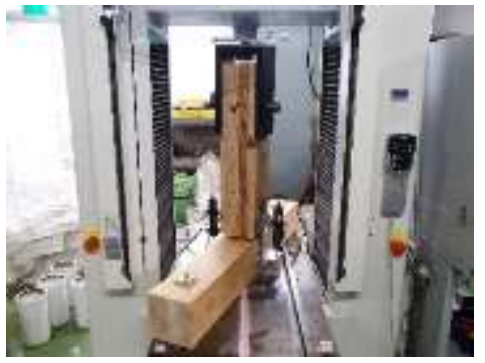

Figure 22: Loading instrument

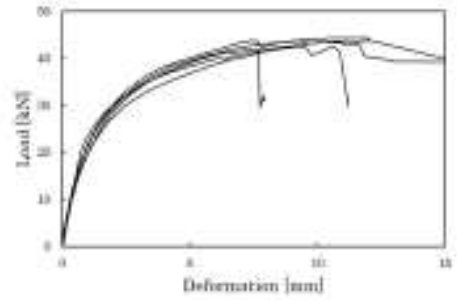

Figure 23: Relationship between load and deformation

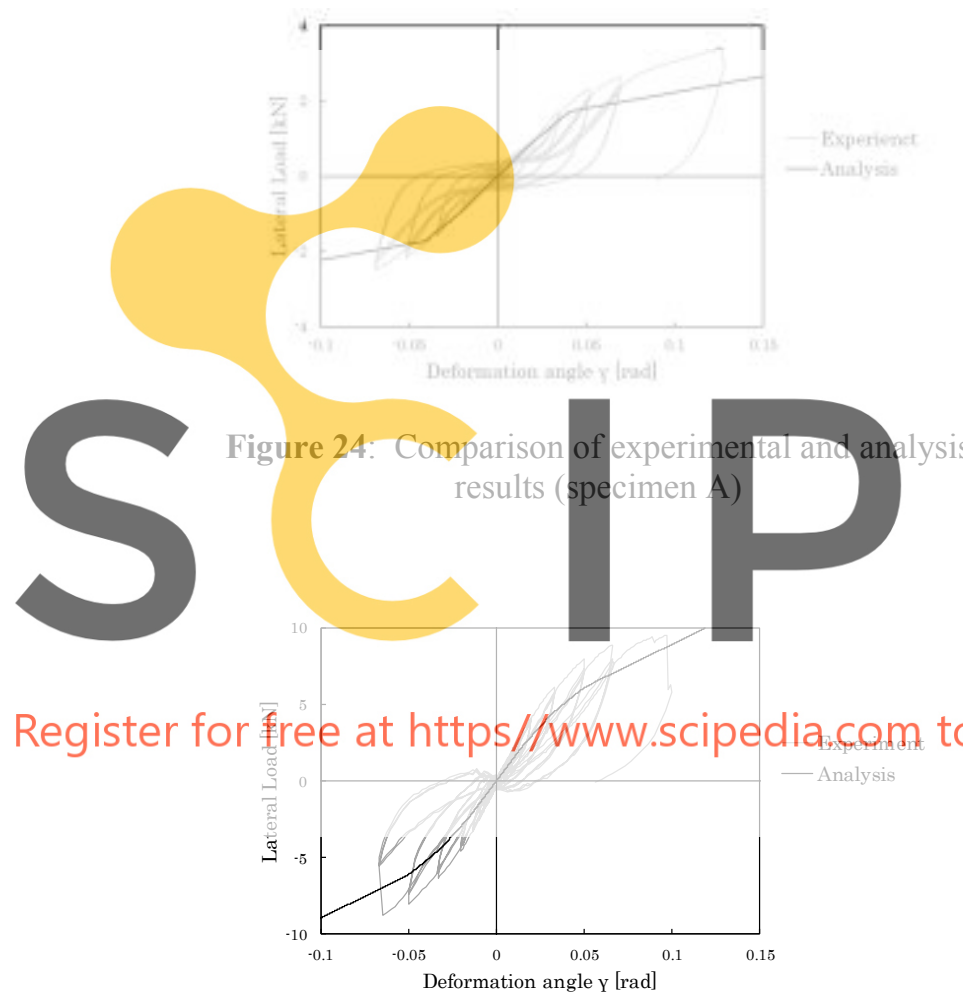

Figure 26: Comparison of experimental and analysis results (specimen C)
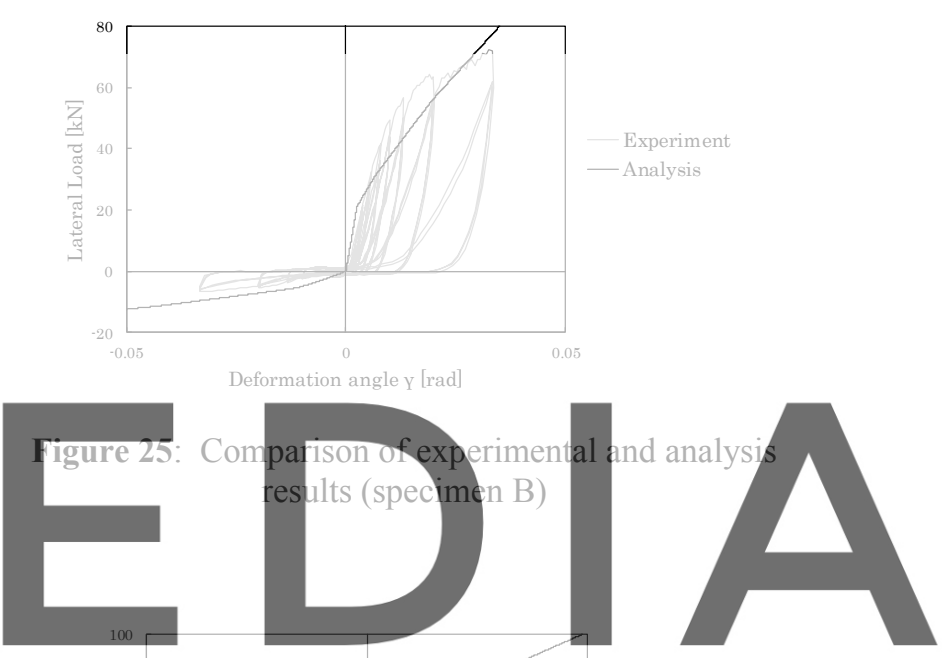

download the version without the watermark

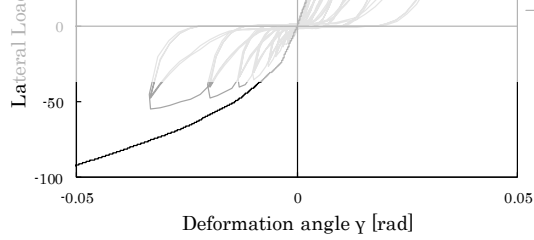

Figure 27: Comparison of experimental and analysis results (specimen D)

column-to-groundsill connection was conducted as shown in Figures 21 to 23. The specimen size was the same as that for the full-scale static lateral loading tests. The number of specimens was five. The embedment resistance at the connection of the through brace, separate brace, or knee brace and the beam, groundsill, or column was expressed as an axis spring. The shear and tensile resistance of a bolt were expressed as an axis spring. A bilinear-hysteresis model was used for each rotation spring and axis spring. The initial stiffness and yield moment or strength were calculated based on a previous study [2] [3]. The material property was estimated through the results of destructive tests for each wooden member based on a previous study [2] [4]. 
The static pushover analysis was performed using a general-purpose analysis software, i.e., SNAP (Ver. 7). Figures 24 to 27 show the comparison of the relationship between the load and deformation angle of each specimen as obtained from the test and analysis results. The analysis results are in good agreement with the test results for each specimen. The load to the range of a large deformation angle on almost all specimens obtained through the analysis is smaller than that obtained in the tests because the design equations were used for calculation.

\subsection{Modeling to a 3D frame}

The 3D-frame model was proposed based on the 2D-frame models. Their validity was examined by comparing the test and analysis results. The external walls at X1, X25, Y2, and Y7 were plastered with a mortar and mud wall that were $20 \mathrm{~mm}$ and $10 \mathrm{~mm}$ thick, respectively. They were not considered as a seismic element due to their small thickness. The small section braces of $90 \times 90 \mathrm{~mm}$ were located in the longitudinal direction at Y2, Y3, and Y7 as shown in Figures 6 to 8, but they are not considered as a seismic element because of their dimension
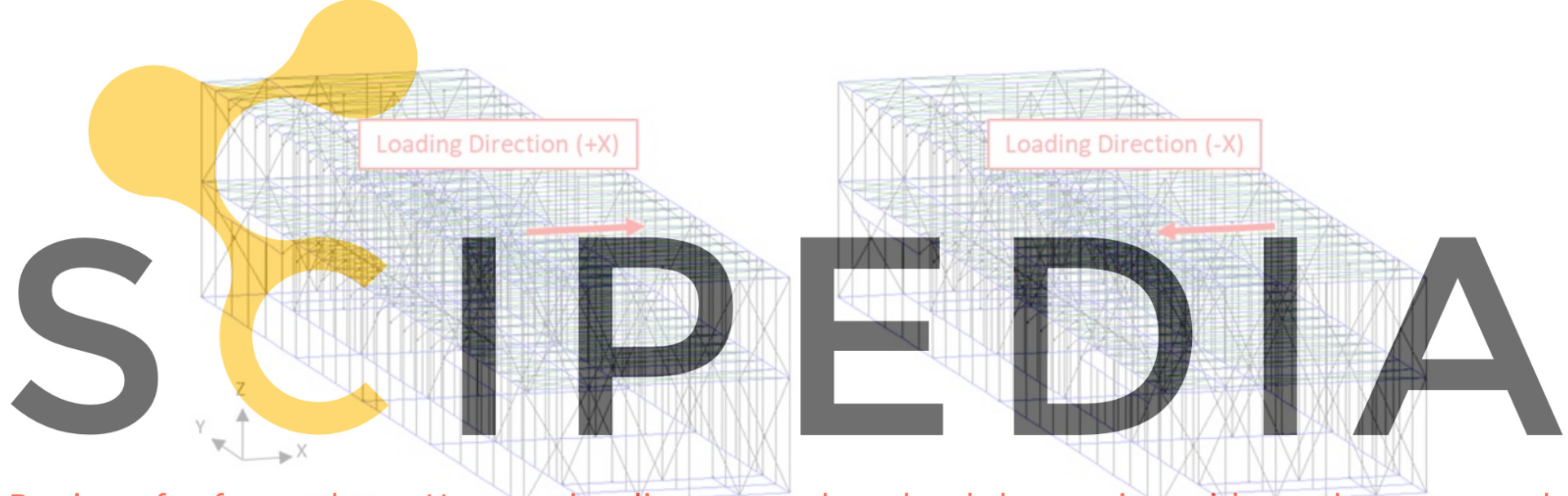

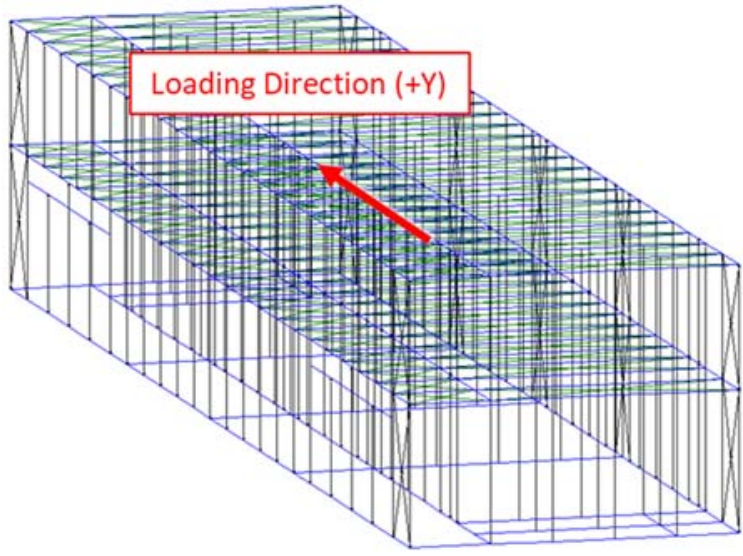

Figure 30: 3D-frame model ( $+\mathrm{Y}$ direction)

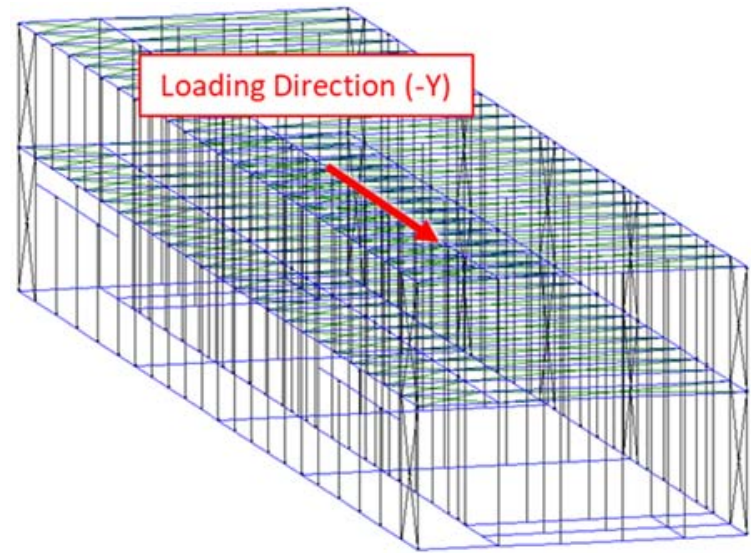

Figure 31: 3D-frame model (-Y direction) 
which were smaller than the large section braces of $135 \times 135 \mathrm{~mm}$. The axis behavior at the top and bottom of the column-to-groundsill or column-to-beam connections was expressed as an axis spring with a bilinear-hysteresis model. Regarding the embedment behavior, the initial stiffness and yield strength were calculated based on a previous study [2] [3]. Regarding the uplift behavior, the initial stiffness and yield strength were decided based on the results of tensile tests for column-to-groundsill connection as shown in Figures 21 to 23. The material property was estimated based on a previous study [2] and the second stiffness was determined to be $1 / 8^{\text {th }}$ of the initial stiffness.

The 3D-frame model was not including the roof frame because the deformation of roof frame was very small. The horizontal frame such as a floor or roof was expressed as a brace with a bilinear hysteresis model. The initial stiffness and yield strength were estimated based on a previous study [5]. The second stiffness was determined to be 0 of the initial stiffness, i.e., the elastic-perfectly plastic model.

Figures 28 to 31 show the 3D-frame model of the north school buildings of Yashiro Junior High School. Owing to the limitation of the nodal points number in an analytical software, the 3D-frame model was divided into four. For example, $+\mathrm{X}$ and $-\mathrm{X}$ direction models were considering the seismic elements in the $\mathrm{X}$ direction.

\section{SEISMIC PERFORMANCE OF A MODERN WOODEN SCHOOL BUILDING}

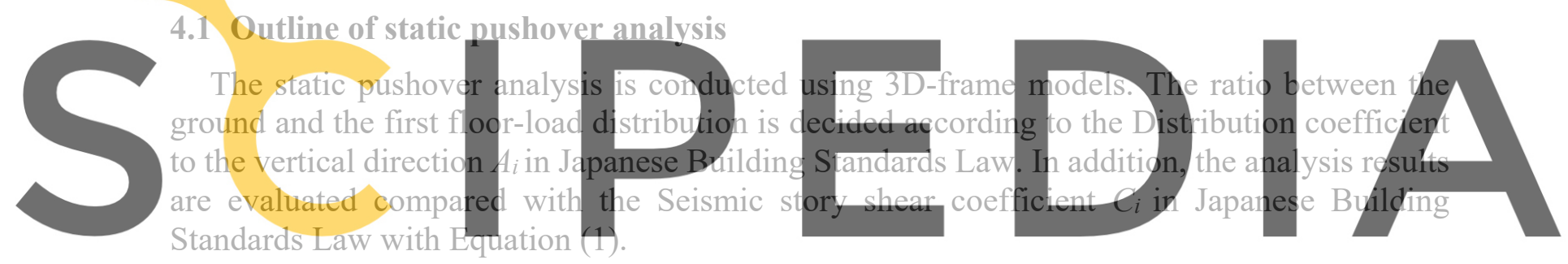

Register for free at https//www.scipedia.com to download the version without the watermark where, $Z$ is Seismic zone coefficient (in case of Ehime Prefecture 0.9). $R_{t}$ is the Vibration characteristics coefficient calculated by Design first natural period $T$. $C_{0}$ is the Standard shear coefficient (in case of moderate earthquake 0.2 and large earthquake 1.0). Table 1 summarizes the calculation result.

Table 1: Calculation result of the seismic story shear coefficient

\begin{tabular}{|c|c|c|c|c|c|c|}
\hline Earthquake & Story & $Z$ & $R_{t}$ & $A_{i}$ & $C_{0}$ & $C_{i}$ \\
\hline \multirow{2}{*}{ Moderate } & 2 & \multirow{4}{*}{0.9} & \multirow{4}{*}{1.0} & 1.43 & \multirow{2}{*}{0.2} & 0.26 \\
\hline & 1 & & & 1.00 & & 0.18 \\
\hline \multirow{2}{*}{ Large } & 2 & & & 1.43 & \multirow{2}{*}{1.0} & 1.3 \\
\hline & 1 & & & 1.00 & & 0.90 \\
\hline
\end{tabular}

The deformation capacity of a modern wooden school building is evaluated at the top and bottom of the column-to-groundsill or column-to-beam connections. The strength of embedment resistance at the connections continues to increase, on the other hand, the strength of tensile resistance suddenly decreases after the fracture at the connections. Accordingly, the deformation capacity is evaluated by the average yield and ultimate deformation, based on the 
results of the tensile test for column-to-groundsill connection. The average yield deformation and the ultimate yield deformation are $4.96 \mathrm{~mm}$ and $9.38 \mathrm{~mm}$, respectively.

\subsection{Results of static pushover analysis}

Figures 32 and 33 show the relationship between the story deformation angle and the story shear coefficient from the results of the static pushover analysis. The story shear coefficient is given by the ratio of the story shear force divided by the seismic weight. In these figures, the axis spring deformation at one side of the column-to-groundsill connection reaches a yield deformation of $4.96 \mathrm{~mm}$ at the yield point and an ultimate deformation of $9.38 \mathrm{~mm}$ at the ultimate point. If the elastic limit of a modern wooden school building is assumed to be 1/120 $\mathrm{rad}$, the story shear coefficient at the ground floor is 0.27 in the $\mathrm{X}$ direction and 0.10 in the $\mathrm{Y}$ direction, that at the first floor is 0.86 in the $\mathrm{X}$ direction and 0.18 in the $\mathrm{Y}$ direction. In contrast, the required seismic story shear coefficient $C_{i}$ for moderate earthquakes is 0.18 at the ground floor and 0.26 at the first floor as shown in Table 1 . Therefore, the seismic performance at both floors in the $\mathrm{Y}$ direction is insufficient. When the axis spring deformation at one side of the column-to-groundsill connection reaches yield deformation, the story deformation angle reaches $1 / 31 \mathrm{rad}$ in the $\mathrm{X}$ direction and $1 / 48 \mathrm{rad}$ in the $\mathrm{Y}$ direction at the ground floor, and $1 / 167$ rad in the $\mathrm{X}$ direction and $1 / 83 \mathrm{rad}$ in the $\mathrm{Y}$ direction at the first floor. The story deformation angle of a modern wooden school building exceeds the elastic limit of 1/120 rad except for the $\mathrm{X}$ direction at the first floor. When a modern wooden school building reaches the ultimate limit, the story shear coeffici direction, that at the other hand, the required ground floor and 1.3 at especially the deformat both directions is insufficient.
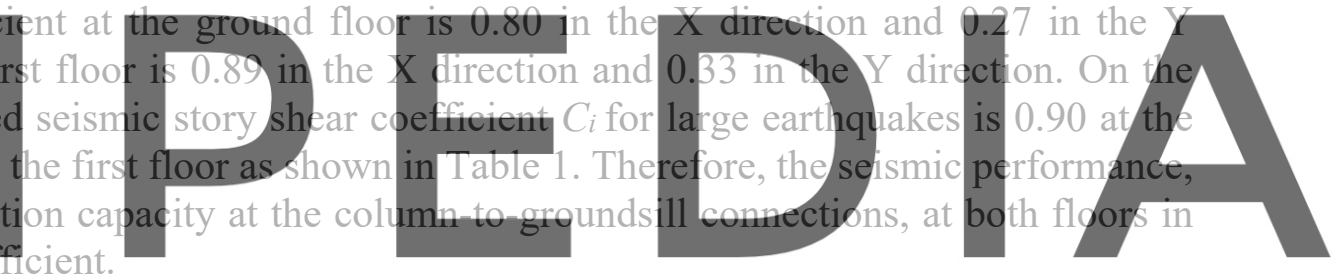

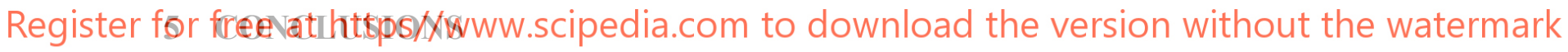

In this study, a static pushover analysis was conducted for a modern wooden school building

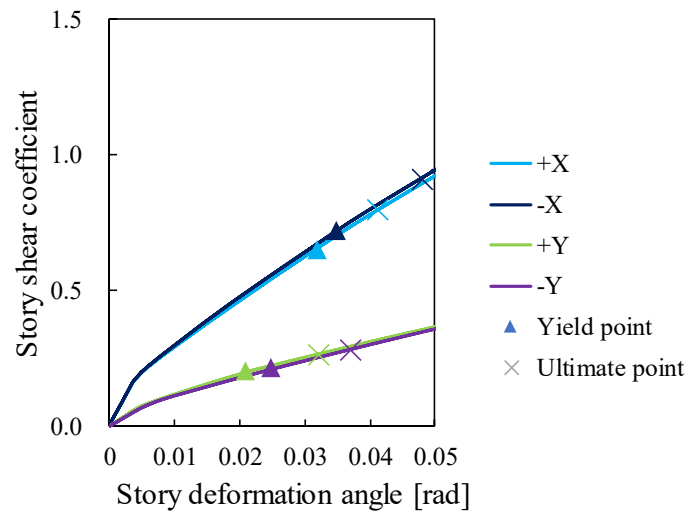

Figure 32: Analysis results (Ground floor)

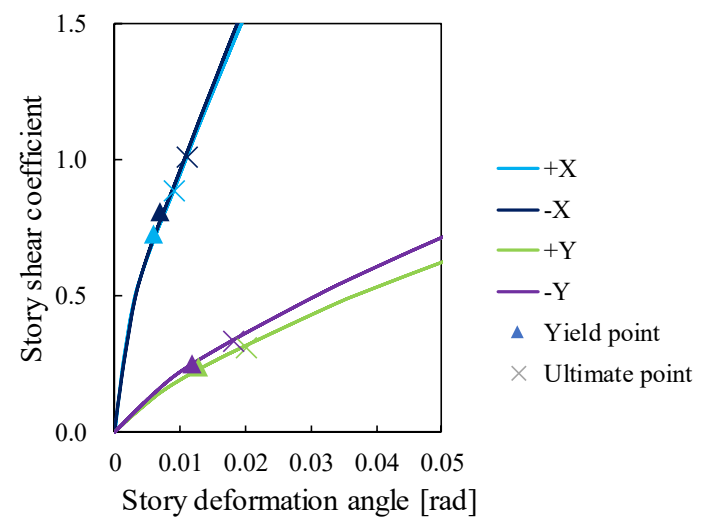

Figure 33: Analysis results (First floor) 
using a 3D-frame model to simulate the relationship between lateral load and deformation. This $3 \mathrm{D}$-frame model was proposed based on the site investigation and 2D-frame model in a previous study.

From the analysis results, the required bearing capacity to moderate and large earthquakes was insufficient in the longitudinal direction ( $\mathrm{Y}$ direction). In the transverse direction (X direction), the required bearing capacity for large earthquakes was insufficient. The bearing capacity was decided by the deformation capacity of the column-to-groundsill connection. Therefore, the reinforcement to these connections were required to improve the seismic performance of a modern wooden school building.

\section{Acknowledgments}

This research was partially supported by the Asahi Glass Foundation. We gratefully acknowledge this support.

\section{REFERENCES}

[1] Ebisuoka, M., and Miyamoto, M., Study on Seismic Performance of Timber Frame Used for Modern Timber School Building, AIJ Journal of Structural Engineering, 64B, 453-461, March 2018.

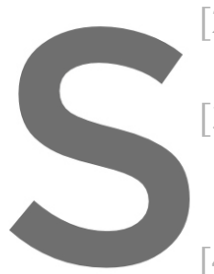

[2] Architectural Institate Structures, Maruzen,

[3] Sakata, H., Yamazar Shear Behavior Construction Engine
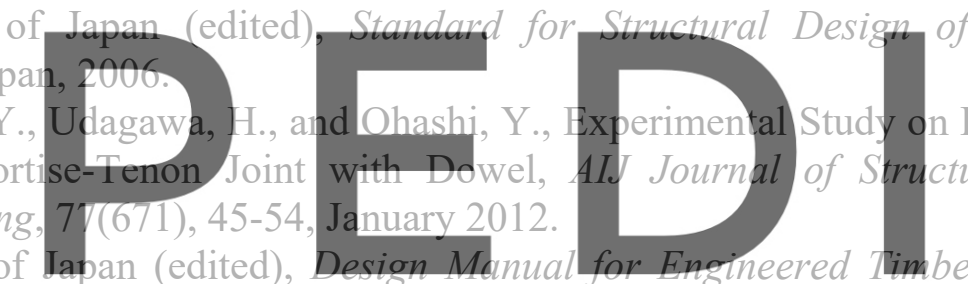
Timber Maruzen, Japan, 2009.

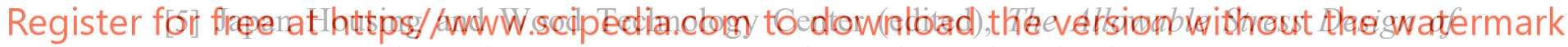
Conventional Wooden Houses, Japan Housing and Wood Technology Center, Japan, 2008. 